Please cite as:

Jung, T., tom Dieck, M.C., Rauschnabel, P., Ascenção, M., Tuominen, P. \& Moilanen, T. (2017). Functional, Hedonic or Social? Exploring Antecedents and Consequences of Virtual Reality Rollercoaster Usage. In T. Jung \& M. Claudia tom Dieck (Eds.). Augmented Reality and Virtual Reality - Empowering Human, Place and Business, Springer. Forthcoming.

\title{
Functional, Hedonic or Social? Exploring Antecedents and Consequences of Virtual Reality Rollercoaster Usage
}

\author{
Timothy Jung a \\ M. Claudia tom Dieck ${ }^{\mathrm{a}}$ \\ Philipp Rauschnabel ${ }^{\mathrm{b}}$ \\ Mario Ascenção ${ }^{c}$, \\ Pasi Tuominen ${ }^{\mathrm{c}}$, \\ Teemu Moilanen ${ }^{\mathrm{c}}$ \\ ${ }^{a}$ Faculty of Business and Law \\ Manchester Metropolitan University, United Kingdom \\ \{t.jung\}\{c.tom-dieck\}@mmu.ac.uk \\ ${ }^{\mathrm{b}}$ Department of Management Studies, College of Business \\ University of Michigan - Dearborn, USA \\ prausch@umich.edu \\ ${ }^{\mathrm{c}}$ Experience and Wellness Economy unit / Haaga Campus \\ Haaga-Helia University of Applied Sciences, Finland \\ \{mariopassos.ascencao\}\{pasi.tuominen\} \{teemu.moilanen\}@haaga-helia.fi
}

\begin{abstract}
During the last years, various media technologies such as Augmented Reality (AR) and Virtual Reality (VR) have gained increased attention in consumer markets and tourism. For theme parks, especially those with rollercoasters, wearable VR devices are expected to be associated with various benefits for tourists' experience. Therefore, adventure park managers with VR rollercoasters have a keen interest in understanding the drivers and psychological mechanisms of their visitors, especially those associated with economic benefits. Against this background, this study provides a conceptual model grounded in the VR and AR literature. The model is then tested in a Finnish amusement park with a VR switchback, and analysed using structural equation modelling. Result show that entertainment value and service quality drive satisfaction and subsequently word of mouth, but results do not confirm the importance on visitors' willingness to pay an extra fee for a VR experience. However, this economically crucial variable is determined by social presence of other people, indicating that visitors are willing to pay for experiencing an immersive experience with other people. Theoretical and managerial implications are derived, and avenues for further research discussed.
\end{abstract}

Keywords: Virtual reality; tourism experience; theme park 


\section{Introduction}

The creation of immersive and enjoyable virtual reality (VR) applications for the enhancement of the tourist experience has received increased attention over the last few years which can be largely linked to latest developments in head mounted displays (HMD) (Guttentag, 2010; Jung et al., 2016). Within the tourism context, there are two different approaches to VR experiences: 1. Off-site experience and 2. On-site experience. While off-site experiences provide tourists with an opportunity to explore a destination and trip planning, on-site experiences can be an ideal tool to enhance the existing offering (Jung et al., 2017). Hotel chains such as Marriott used VR simulations to show case their hotels around the world and thus, provide potential hotel guests' with intentions to visit (Marriott, 2014). On the other hand, Geevor Tin Mine museum is an example of an on-site VR experience whereby visitors had the opportunity to experience an underground mine, which would normally be inaccessible (Jung et al., 2016). Although these use cases exist around the world, tourism research with regards to tourists' behavioural intentions after experiencing on-site VR is still limited.

These new virtual environments have various implications for marketers (Chauhan \& Kumar, 2012; Stockinger, 2016). In particular, for theme parks, especially those with rollercoasters, wearable VR devices are expected to be associated with various benefits for tourists' experience (Baker, 2016). Therefore, theme park managers with VR rollercoasters have a keen interest in understanding the drivers and psychological mechanisms of their visitors, especially those associated with economic benefits. Against this background, this study provides and tests a conceptual model grounded in the VR literature.

Furthermore, the competition between theme and amusement parks is fiery, and it is expected that the next battle ground will be about the use of AR and VR technology. In this context, Finland is the first of the Nordic countries to offer rides which combine a rollercoaster with virtual reality. This ride used in this study allowed visitors to experience space scenery, in 360 degrees through a video animation, where they dodged planets at high speed. The music that played in the background was specifically composed for this ride.

During the rollercoaster ride visitors wear a virtual reality headset with a high-quality widescreen image. The VR headset seamlessly combined a real rollercoaster ride with a virtual world. Acceleration and distance sensors were constantly synchronising the 360-degree virtual image as the ride moved around.

Previous studies in the technology adoption context found a number of antecedents that influence users' satisfaction and behavioural intentions including functional benefits, hedonic experience and social experiences (Jung et al., 2015; Rauschnabel \& Ro, 2016; Algharabat \& Zamil, 2013). However, research within the VR tourism context is limited. In particular, a focus on positive word of mouth (WOM) and willingness to pay extra after experiencing technologies has reviewed limited attention within the tourism context. This however, is crucial in order to create compelling business cases for tourism companies. Therefore, the proposed model will test these drivers to provide meaningful recommendations. 


\section{Theoretical Background and Hypotheses Development}

Our conceptual model is summarized in Figure 1 and inspired by prior media and VR research. The model theorizes that consumers' evaluation and reaction to VR rollercoasters is driven by functional, hedonic and social benefits. In particular, the framework proposes specific constructs that address functional, hedonic and social needs which determine visitor's satisfaction, which then indirectly impacts Word of Mouth (WOM) and willingness to pay extra for the VR experience. Inspired by prior technology acceptance and media theories, we also propose that the behavioural variables are also directly influenced by social factors, such as social presence. In the subsequent section, we will derive, define and propose specific constructs and their role in our framework, before empirically testing the model.

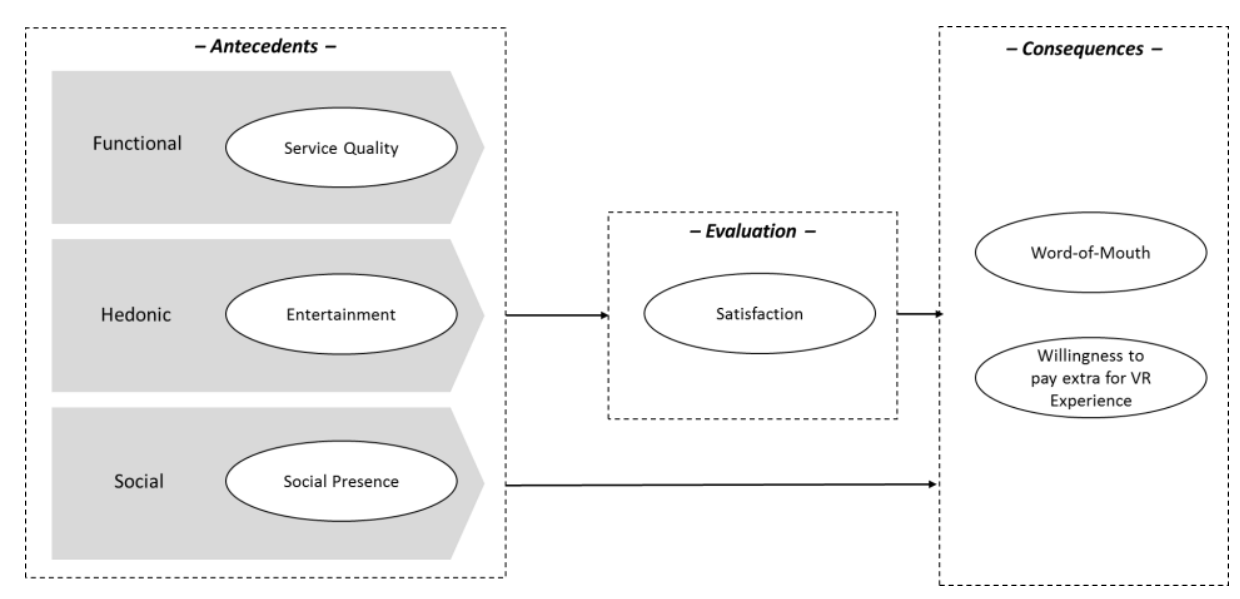

Fig. 1. Proposed Model

\subsection{Service quality and satisfaction}

A recent study, focusing on mobile acceptance, confirmed the link between quality, satisfaction and the intention to re-use mobile services (Ansari et al., 2013). In fact, numerous studies (Baker and Crompton 2000; Petrick, 2004) were conducted in the tourism context regarding perceived quality and its impacts on tourism businesses and Chen and Chen (2010) suggested that service quality is the key determinant for tourists' perceived quality with a high influence on customer satisfaction.

Therefore, we propose:

H1: Service quality has a positive effect on satisfaction. 


\subsection{Entertainment and satisfaction}

Theme parks and hedonic experiences go in hand in hand due to the nature of the business and visitor experience (Balloffet et al., 2014). Psychologically, hedonic experiences are linked with various positive outcomes, such as pleasure and reduction of boredom (Close and Kukar-Kinney, 2010; Klinger, 1971). Therefore, numerous studies on technology acceptance in general (Venkatesh and Bala, 2008; Venkatesh et al., 2012), but also in related contexts such as AR technologies (Balog and Primeanu, 2010; Olsson et al., 2013) have empirically validated that hedonic factors drive users' evaluation of technologies. Wong and Cheung (1999, p. 328) explored motivations to visit theme parks and confirmed visitors' "need to enjoy the adventure and excitement of the rides and the level of importance assigned to the adventure theme" as one of the key aspects of theme park businesses. This clearly shows the strong importance of hedonic experiences within the theme park context. Adding to this, previous studies found that VR creates enjoyable and entertaining experiences (Jung et al., 2016) and thus, we propose:

H2: Entertainment has a positive effect on satisfaction.

\subsection{Social presence and behavioural intentions}

The effect of social experiences on behavioural intentions has been well supported by a long stream of technology adoption literature (e.g. Hsu and Lin, 2008; Qin et al., 2011; tom Dieck et al., 2017). Also in the context of VR, social presence plays an important role within literature (Jung et al., 2016). Within the present study, social presence can be explained by "whether there is positive interpersonal and emotional connection between communicators" (Cui et al., 2012, p. 663).

Because the use of a rollercoaster is an incident-based activity (rather than adopting or buying a new technology), we propose that social factors especially during the experience matter. Therefore, as studied in the context of VR, social presence plays an important role within literature (Jung et al., 2016). Within the present study, social presence can be explained by "whether there is positive interpersonal and emotional connection between communicators" (Cui et al., 2012, p. 663). People tend to find social interactions generally enjoyable (Ryan and Deci, 2000). Consumption experiences, such as brand clubs or communities in the real world or in virtual worlds (e.g. social media) can help consumers to meet these social needs. Virtual experience, especially while riding a rollercoaster, does not allow the creation of 'real' social relationships, and therefore, might trigger more a 'sense of community'. Anyhow, prior research has shown that evoking the feelings of social interactions can evoke positive feelings. For example, people perceive a "sense of community" around brands (Bergkvist and Bech-Larsen, 2010) or think of some brands in terms of human attributes (Rauschnabel and Ahuvia 2014). We therefore propose that if using a VR rollercoaster triggers social perceptions, this should lead to a more positive evaluation. Likewise, we also propose a direct effect on the intentional variables. This is, on the one hand, as technology acceptance theories widely replicate that social influences in general are related to intentional variables. On the other hand, prior research has argued that people tend to consume in an 'instrumental' effect (Ahuvia, 2015). Following this stream of research, people could be willing to engage in VR rollercoasters because of 
gratifications from these social factors, rather a higher and more functional level of 'satisfaction'. Therefore, we propose:

H3: Social presence has a positive effect on satisfaction.

H4: Social presence has a positive effect on willingness to pay.

H5: Social presence has a positive effect on word of mouth.

\subsection{Satisfaction and behavioural intentions}

Although it was argued that behavioural intentions or post-purchase intentions are a result of the satisfaction level of consumers, Fishbein and Manfredo (1992) stated that social behaviours are affected by consumer intentions and thus, can be predicted if properly measured. Wang et al. (2004) defined behavioural intentions as consumers' decision to revisit or repurchase with the same supplier, as well as sharing their experiences in their social circles, the concept of WOM. Harrisson-Walker (2001) argued that since many non-informed consumers heavily rely on others' opinions, the process of WOM to tell others about their experience with the result of influencing potential consumers' behaviour has become more important compared to other external marketing strategies. Furthermore, it was found that high quality perceptions had a positive influence on intended behaviour (Zeithaml et al., 1996). In addition, Choi et al. (2011, p. 191), using the technology acceptance model as a theoretical foundation, concluded that "if the users are satisfied with mobile tour services, the possibility to reuse these services will be high" which was supported by Chou et al. (2013) who focused on the expectancy confirmation theory in the mobile application context. Moreover, a research by Ansari et al. (2013) investigating the value, image, quality, satisfaction and behavioural intention, confirmed that satisfaction has strong positive effects on the intention to re-use mobile value-added services. Adding to this, Luarn and Lin (2003) and Vranakis et al. (2012) identified that one of the most influencing factors affecting loyalty in the e-service or mobile context is customer satisfaction. According to Sun et al. (2013), satisfaction results in returning visitors and higher profits. However, limited research has tested these relationships within the VR tourism context. With regards to behavioural intentions, for theme parks, positive WOM and willingness to pay for services are considered immensely important and therefore we propose:

H6: Satisfaction has a positive effect on willingness to pay.

H7: Satisfaction has a positive effect on word of mouth.

\section{Methods}

\subsection{Data Collection}

The data collection was conducted in one of the major amusement parks in Finland. Data were gathered from respondents who experienced a VR rollercoaster, using Samsung Gear VR glasses, between September 23 and October 22, 2016. Convenience sampling method was used by sending an e-mail invitation to 1575 adult higher education students. Students, who replied to the call for participation in the study, were informed about the nature of the research project. Thereafter, if they agreed, participants were given ride tickets, and informed to visit amusement park, with one 
friend, any day of their choice. A questionnaire was handed with ride tickets, and the participants were asked to fill it after the experience. 152 usable responses of the VR enhanced "milky way" rollercoaster experience were collected.

\subsection{Measures}

If possible, we adopted existing scales from the literature. Scales were measured using a 5-point Likert scale. Higher values indicate stronger agreement or more positive evaluations. All items and references are listed in Table 2. We started our analyses with an inspection of the factorial structure of the constructs. On a global level, CFA results show good psychometric properties (Chi2 = 180.0; $\mathrm{df}=.120 ; \mathrm{p}<.001 ; \mathrm{CFI}=.960$; TLI=.950; SRMR=.048; RMSEA=.062). Similarly, fit indices on a local level indicated exceeded the recommended thresholds of .5, .7, and .7 for AVE, C.R. and Cronbach's alpha. In addition, all factor loading exceeded .7 and were significant on a $p<.001$-level. Table 2 shows the measurement items and the fit measures, and Table 1 presents the correlations.

Table 1. Correlation

\begin{tabular}{llllll}
\hline Matrix & 1 & 2 & 3 & 4 & 5 \\
\hline 1 Entertainment & & & & & \\
2 Quality & 0.42 & & & & \\
3 Social presence & 0.14 & 0.30 & & & \\
4 Satisfaction & 0.80 & 0.71 & 0.15 & & \\
5 Word of Moth & 0.69 & 0.62 & 0.26 & 0.79 & \\
6 Additional Payment & 0.22 & 0.27 & 0.33 & 0.18 & 0.35 \\
\hline
\end{tabular}

Table 2. CFA Model

\begin{tabular}{|c|c|c|c|}
\hline Construct and measurement items & $\delta$ & CR & AVE \\
\hline Entertainment (Loureiro, 2014) & & .90 & .70 \\
\hline The rollercoaster VR experience was amusing & .88 & & \\
\hline The rollercoaster VR experience was entertaining & .85 & & \\
\hline The rollercoaster VR experience was fun & .80 & & \\
\hline The rollercoaster VR experience was captivating & .80 & & \\
\hline Service Quality (Yang et al., 2005) & & .83 & .62 \\
\hline $\begin{array}{l}\text { How do you perceive your rollercoaster facility quality of the Linnunrata } \\
\text { eXtra }\end{array}$ & .74 & & \\
\hline $\begin{array}{l}\text { How do you perceive your rollercoaster VR quality of the Linnunrata } \\
\text { eXtra } 12345\end{array}$ & .78 & & \\
\hline $\begin{array}{l}\text { How do you perceive your overall quality of the Linnunrata eXtra } \\
\text { experience }\end{array}$ & .84 & & \\
\hline Social Presence (Cyr et al., 2007) & & .84 & .64 \\
\hline $\begin{array}{l}\text { There was a sense of human contact when I had the rollercoaster VR } \\
\text { experience }\end{array}$ & .84 & & \\
\hline $\begin{array}{l}\text { There was a sense of sociability when I had the rollercoaster VR } \\
\text { experience }\end{array}$ & .80 & & \\
\hline
\end{tabular}


There was a sense of human warmth when I had the rollercoaster VR experience

.76

Satisfaction (Quadri-Felitti \& Fiore, 2013)

How do you feel about your overall rollercoaster VR experience? (1=dissatisfied... $5=$ satisfied $)$

How do you feel about your overall rollercoaster VR experience? ( $1=$ displeased...5=pleased $)$

How do you feel about your overall rollercoaster VR experience?

( $1=$ frustrated...5=contended)

Word of Mouth (Quadri-Felitti \& Fiore, 2013)

I want to recommend Linnanmäki to others after experiencing the Linnunrata eXtra

I am likely to recommend Linnanmäki to others after experiencing the Linnunrata eXtra

How likely is it that you would recommend Linnunrata eXtra to a friend, colleague or relative?

Willingness to Pay (Bloemer \& Odekerken-Schroder, 2002)

I intend to pay extra entrance fee if this VR experience is included

I am willing to pay extra for additional VR experiences

\section{Findings}

\subsection{Hypotheses Testing}

In order to test the hypothesized effect, we modelled structural relationships between the hypothesized model. In addition, we included age and gender as control variables on the three endogenous variables to parcel out variance from respondents' demographic characteristics. We assessed the structural equation model in Mplus using a maximum likelihood estimator with robust error terms. Results indicate acceptable levels of fit $(\mathrm{Chi} 2=217.84 ; \mathrm{df}=154 ; \mathrm{p}<.001 ; \mathrm{CFI}=.958 ; \mathrm{TLI}=.948 ; \mathrm{SRMR}=.059$; RMSEA=.057). We will discuss all effects (standardized beta effects) in detail below and summarize the findings in Figure 2. Results show two significant antecedents of satisfaction, namely quality $(\beta=.488 ; p<.001)$ and Entertainment $(\beta=.621 ; p<.001)$, supporting $\mathrm{H} 1$ and $\mathrm{H} 2$. However, results do not support the hypothesized effect for social presence $(\beta=-.077 ; \mathrm{p}=.246)$. Both control variables were insignificant (age: $\beta=.009 ; \mathrm{p}=.871$; gender: $\beta=.024 ; \mathrm{p}=.661$ ). The model explains $84.4 \%$ of satisfaction's variance $(\mathrm{p}<.001)$.

Findings also show that satisfaction is positively related to word of mouth $(\beta=.779$; $\mathrm{p}<.001)$ but not on willingness to pay ( $\beta=.142 ; \mathrm{p}=.162)$. This supports H7 but not H6. Both word of mouth $(\beta=.174 ; \mathrm{p}=.014)$ and willingness to pay $(\beta=.323 ; \mathrm{p}=.001)$ are significantly influenced by social presence, which is in line with $\mathrm{H} 4$ and $\mathrm{H} 5$. The model explains $22.2 \%$ of the variation of willingness to pay, and $69.5 \%$ of word of mouth. The control variables were insignificant for word of mouth (age: $\beta=.075 ; p=.340$ ) but showed that males and older consumers are more likely to pay extra for the VR experience (age: $\beta=.185 ; p=.030$; gender: $\beta=-.187 ; p=.036$ ). 


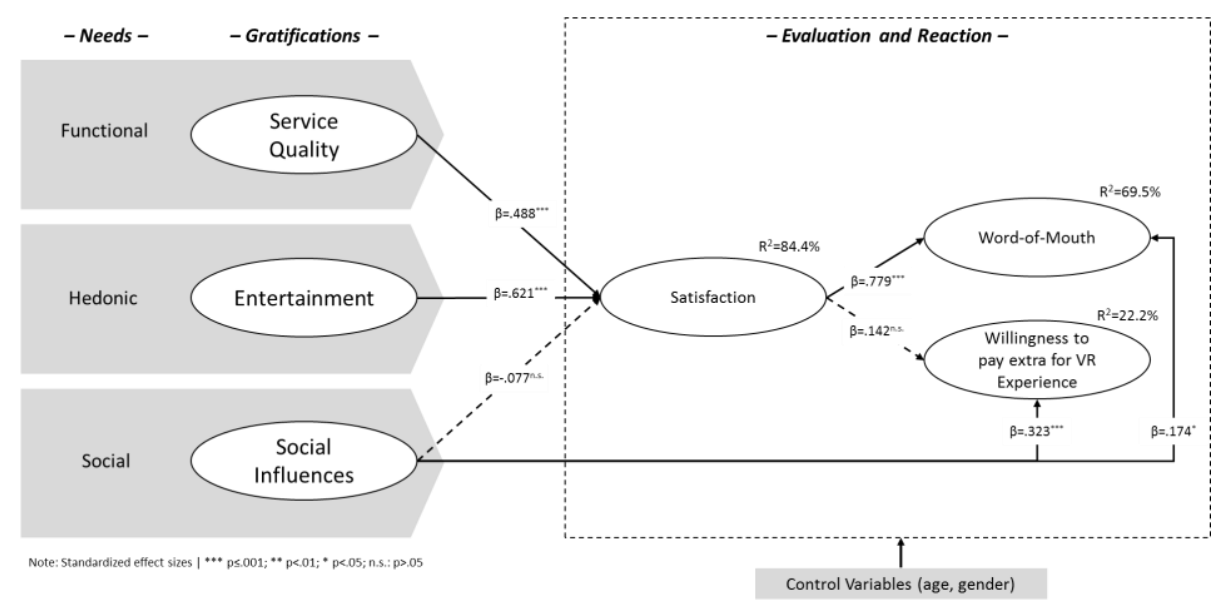

Fig. 2. Summary of the results

\subsection{Robustness Tests}

To further assess the robustness of the findings, we re-estimated the model with different estimators. We also ran the model without control variables. The effects hold. We also modelled direct effects from entertainment and quality on the intentional variables; they did not reach significance. In sum, findings from the robustness tests lead to the conclusion that the reported results are stable.

\section{Discussion and Conclusion}

The present study incorporates, extends and modifies previous theories which looked at the relationships between quality, entertainment, social influence, satisfaction and behavioural intention (Ansari et al., 2013; Chen and Chen, 2010; Rauschnabel and Ro, 2015), theorising (at least) three antecedents of visitors' satisfaction and behavioural intentions to recommend and pay the VR rollercoaster experience. Despite potential benefits of VR applications for enhancing tourist experience, previous research in this context is limited and the present study acknowledges this gap and contributes to the existing pool of knowledge. A number of findings emerged throughout this study that contribute to the literature on VR in several ways.

First, we propose a model that explains the emergence and consequences of users' level of satisfaction with VR experiences. In addition, the study looks at two different but crucial outcome variables: word of mouth and willingness to pay for a VR experience. Results show that word of mouth is mostly driven satisfaction, whereas satisfaction was shown to be non-significant for visitors' intention to pay a for the VR experience. In other words, whether a visitor was satisfied or not did not relate to his or her intention to pay more for the VR experience or not. However, this crucial economic variable was significantly impacted by social experiences. 
Second, the proposed model finds two antecedents to satisfaction: service quality and entertainment. In contrast to our hypotheses, social influence does not reach significance. On the one hand, this is somehow similar to the stream of technology acceptance literature, where social norms drive intention but not attitude. A similar effect is observed in this study, where enjoying the VR experience with other people seems not no drive satisfaction (which is similar to the attitudinal variables in the technology acceptance literature), but makes people willing to pay more. The findings also provide several important contributions for managerial practice (Wang, Wang, and Yao, 2009). First of all, the findings provide managers with a solid understanding of factors that determine visitors' satisfaction and intentions. Results also show that relying on customer satisfaction measures alone is not sufficient. In particular, managers need to be aware that satisfaction can lead to positive word of mouth, which nowadays can also be documented in 'social media buzz' (electronic word of mouth), which can result in new visitors. However, in order to achieve economic benefits among existing visitors by increasing prices for VR experiences, managers need to stimulate social factors. More research is needed to identify how this can be done (especially in specific VR contexts).

As any study, this research has some limitations that lead to opportunities for further research. For example, the current research was conducted in a single context (one rollercoaster in Finland) and build on a relatively small sample size. These factor might limit generalisability of the findings, and thus, caution must be taken when extrapolating the findings to other contexts. For example, the impact on cultural values could moderate the proposed effects, in a way that people from individualistic versus collectivists cultures value the social aspects differently. In addition, especially for managers, characteristics of the VR app and the rollercoaster that impact the VR experience are crucial. Future research could investigate how effective combinations of VR apps and rollercoasters look like.

In sum, this study - while being one of the first on VR rollercoaster experiences provides insights into the underlying mechanisms how rollercoasters. The findings provide the basis from further groundwork in the intersection of real-word entertainment and virtual worlds.

\section{References}

Ahuvia, A. C. (2015). Nothing matters more to people than people: Brand meaning and social relationships. Brand meaning management, 121-149.

Algharabat, R. S., \& Zamil, A. M. A. (2013). An empirical investigation of 3D-based information systems success for online retailers. International Journal of Technology Marketing, 8(3), 316-336.

Ansari, A., Kheirabadi, A., Ghalamkari, S. and Khanjari, A.R. (2013). Investigation the Relationship among Mobile Value-added Services Quality, Customer Satisfaction and the Continuance Intention: Case Study, Hamrah Avval Operator, International Journal of Information Science and Management, Special Issue ECDC 2013: 67-84.

Baker, C. A. (2016). Creative choices and fan practices in the transformation of theme park space. Transformative Works and Cultures, 22: 1-1.

Baker, D.A. and Crompton, J.L. (2000). Quality, satisfaction and behavioural intentions. Annals of Tourism Research, 27(3): 785-804. 
Balloffet, P., Courvoisier, F. H., \& Lagier, J. (2014). From museum to amusement park: The opportunities and risks of edutainment. International Journal of Arts Management, 16(2): 4-17.

Balog, A., and Pribeanu, C. (2010). The role of perceived enjoyment in the students' acceptance of an augmented reality teaching platform: A structural equation modelling approach. Studies in Informatics and Control, 19(3): 319-330.

Bergkvist, L., and Bech-Larsen, T. (2010). Two studies of consequences and actionable antecedents of brand love. Journal of Brand Management, 17(7): 504-518.

Bloemer, J., \& Odekerken-Schroder, G. (2002). Store satisfaction and store loyalty explained by customer-and store-related factors. Journal of Consumer Satisfaction, Dissatisfaction and Complaining Behavior, 15, 68.

Chauhan, R., \& Kumar, G. (2012). Virtual business empires at Second Life. International Journal of Technology Marketing, 7(3), 254-266.

Chen, C. F. and Chen, F. S. (2010). Experience Quality, Perceived Value, Satisfaction and Behavioral Intentions for Heritage Tourists. Tourism Management, 31(1): 29-35.

Choi, H.S., Park, J.W. and Park, S.B. (2011). A Study on the Effect of Mobile Tourism Information Services on Tourist Satisfaction and Continual Reuse. Int. J Busi. Inf. Tech, 1(3), 189-195.

Chou, C.H., Chiu, C.H., Ho, C.Y. and Lee, C.J. (2013). Understanding Mobile Apps Continuance Usage Behaviour and Habit: An Expectance-Confirmation Theory", Available at: http://www.pacis-net.org/file/2013/PACIS2013-132.pdf [Accessed March 14, 2014].

Close, A. G., and Kukar-Kinney, M. (2010). Beyond buying: Motivations behind consumers' online shopping cart use. Journal of Business Research, 63(9): 986-992.

Cui, G., Lockee, B. and Meng, C. (2013). Building modern online social presence: A review of social presence theory and its instructional design implications for future trends. Education and information technologies, 18(4): 661-685.

Cyr, D., Hassanein, K., Head, M., \& Ivanov, A. (2007). The role of social presence in establishing loyalty in e-service environments. Interacting with computers, 19(1), 43-56.

Fishbein, M. and Manfredo, M.J. (1992). A Theory of Behaviour Change. In Manfredo, M.J. (Ed.), Influencing Human Behaviour: Theory and Applications in Recreation, Tourism and Natural Resources Management, Sagamore, Champaign, USA, pp. 29-50.

Guttentag, D.A. (2010). Virtual reality: Applications and implications for tourism. Tourism Management 31(5): 637-651.

Harrison-Walker, L. J. (2001). The measurement of word-of-mouth communication and an investigation of service quality and customer commitment as potential antecedents. Journal of Service Research, 4(1): 60-75.

Hsu, C. and Lin, J. (2008). Acceptance of blog usage: The roles of technology acceptance, social influence and knowledge sharing motivation. Information and Management, 45: 65-74.

Jung, T., Chung, N., \& Leue, M. C. (2015). The determinants of recommendations to use augmented reality technologies: The case of a Korean theme park. Tourism Management, 49: $75-86$

Jung, T., tom Dieck, M. C., Lee, H. and Chung, N. (2016). Effects of Virtual Reality and Augmented Reality on Visitor Experiences in Museum, In Inversini, A. and Schegg, R. (Eds), Information and Communication Technologies in Tourism. Wien, New York, pp. 621-635, Springer International Publishing.

Jung, T., tom Dieck, M.C., Moorhouse, N. \& tom Dieck, D. (2017). Tourists' Experience of Virtual Reality Applications. Paper presented at ICCE, Las Vegas.

Klinger, E. (1971). Structure and functions of fantasy, John Wiley \& Sons. 
Loureiro, S. M. C. (2014). The role of the rural tourism experience economy in place attachment and behavioral intentions. International Journal of Hospitality Management, 40, 1-9.

Luarn, P. and Lin, H. (2003). A Customer Loyalty Model for E-Service Context. Journal of Electronic Commerce Research, 4(4): 156-167.

Marriott (2014). Available at: https://travel-brilliantly.marriott.com/our-innovations/oculus-getteleported

Muniz, A. M. and O'guinn, T. C. (2001). Brand community. Journal of consumer research, 27(4): 412-432.

Olsson, T., Lagerstam, E., Kärkkäinen, T., \& Väänänen-Vainio-Mattila, K. (2013). Expected user experience of mobile augmented reality services: a user study in the context of shopping centres. Personal and ubiquitous computing, 17(2): 287-304.

Petrick, J. F. (2004). Understanding the relationships of quality, value, equity, satisfaction, and behavioral intentions among golf travellers. Journal of Travel research, 42: 397-407.

Qin, L., Kim, Y., Hsu, J. and Tan, X. (2011). The effects of social influence on user acceptance of online social networks. International Journal of Human-Computer Interaction, 27(9): pp. 885-899

Quadri-Felitti, D., \& Fiore, A.M. (2013). Destination loyalty: Effects of wine tourists' experiences, memories, and satisfaction on intentions. Tourism and Hospitality Research, 1-16.

Rauschnabel, P. A. and Ahuvia, A. C. (2014). You're so lovable: Anthropomorphism and brand love. Journal of Brand Management, 21(5): 372-395.

Rauschnabel, P. A., Brem, A., \& Ivens, B. S. (2015). Who will buy smart glasses? Empirical results of two pre-market-entry studies on the role of personality in individual awareness and intended adoption of Google Glass wearables. Computers in Human Behavior, 49, 635-647.

Rauschnabel, P. A., \& Ro, Y. K. (2016). Augmented reality smart glasses: An investigation of technology acceptance drivers. International Journal of Technology Marketing, 11(2), 123-148.

Stockinger, H. (2016). The future of augmented reality-an Open Delphi study on technology acceptance. International Journal of Technology Marketing, 11(1), 55-96.

Strizhakova, Y., Coulter, R. A. and Price, L. L. (2008). The meanings of branded products: A cross-national scale development and meaning assessment. International Journal of Research in Marketing, 25(2): 82-93.

Sun, X., Chi, C. G. Q. and Xu, H. (2013). Developing Destination Loyalty: The Case of Hainan Island. Annals of Tourism Research, 43, 547-577.

tom Dieck, M. C., \& Jung, T. (2015). A theoretical model of mobile augmented reality acceptance in urban heritage tourism. Current Issues in Tourism, 1-21.

tom Dieck, M. C., Jung, T. H., Kim, W. G. And Moon, Y. (2017). Hotel guests' social media acceptance in luxury hotels. International Journal of Contemporary Hospitality Management, 29(1): 530-550.

Venkatesh, V., \& Bala, H. (2008). Technology acceptance model 3 and a research agenda on interventions. Decision sciences, 39(2), 273-315.

Vranakis, S., Chatzoglou, P. and Mpaloukas, A. (2012). Customer satisfaction of Greek mobile phone services. International Journal of Managing Value and Supply Chains, 3(4), 4354.

Wang, Y., Lo, H. P. and Yang, Y. (2004). An integrated framework for service quality, customer value, satisfaction: Evidence from China's telecommunication industry. Information Systems Frontiers, 6(4), 325-340.

Wang, Y., Wang, K. L., \& Yao, J. T. (2009). Marketing mixes for digital products: a study of the marketspaces in China. International Journal of Technology Marketing, 4(1), 15-42.

Wong, K. K., \& Cheung, P. W. (1999). Strategic theming in theme park marketing. Journal of Vacation Marketing, 5(4), 319-332. 
Yang, Z., Cai, S., Zhou, Z., \& Zhou, N. (2005). Development and validation of an instrument to measure user perceived service quality of information presenting web portals. Information \& Management, 42(4), 575-589.

Zeithaml, V. A., Berry, L.L. and Parasuraman, A. (1996). The Behavioural Consequences of Service Quality. Journal of Marketing, 60(2), 31-46. 